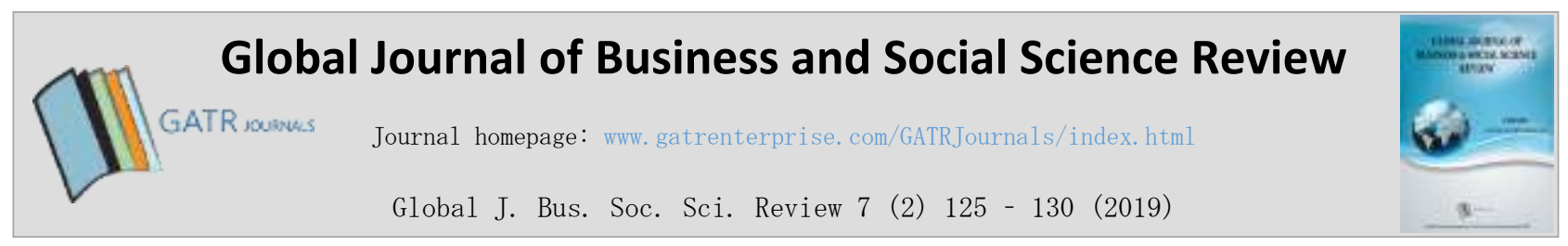

\title{
Self-Concept and Social Adjustment of First-Year Students
}

\author{
Rifa Hidayah*
}

Universitas Islam Negeri Maulana Malik Ibrahim Malang, Indonesia

\begin{abstract}
Objective - Students who study in higher education institutions should have a good socialization process since it later influences their happiness and sadness during their first year of university life. They may face some difficulties and problems that may inhibit their academic success if they cannot adjust well. One of the successful social adjustment criteria is self-concept, in which is derived from interactions with others, for example, the environment. For that reason, it is important to investigate the self-concept and social adjustment of Psychology students, at UIN Maulana Malik Ibrahim Malang, during the first semester. This paper therefore aims to a) determine the degree of student social adjustment, b) determine the quality of self-concept, and c) identify the relationship between self-concept and social adjustment among first year students of Psychology, UIN Maulana Malik Ibrahim Malang.

Methodology/Technique - The subjects of this study include 134 first year students at the Faculty of Psychology, UIN Maulana Malik Ibrahim Malang, East Java. The data was collected in accordance with the scale of self-concept and social adjustment.

Finding \& Novelty - The results show that 1) the degree of first students' self-concept is in average scale, 69.4\%, 2) the social adjustment of first year students belongs to a moderate category, 71,6\%, and 3) self-concept has positive correlation to social adjustment $(\mathrm{r}=0,703, \mathrm{p}=0,000)$. These findings confirm that the higher the self-concept the students poses, the better the social adjustment they perform. This study suggests the need for intervention to escalate self-concept and social adjustment of students by collaborating with some stakeholders, particularly students' parents, universities, government, societies, and religious figures.
\end{abstract}

Type of Paper: Empirical.

Keywords: Self-concept; Social Adjustment; University Students; UIN Maulana Malik Ibrahim Malang Indonesia.

Reference to this paper should be made as follows: Hidayah, R. (2019). Self-Concept and Social Adjustment of FirstYear Students, Global J. Bus. Soc. Sci. Review 7 (2): 125 - 130. https://doi.org/10.35609/gjbssr.2019.7.2(3)

JEL Classification: A20, A22, A29.

\section{Introduction}

First-year students experience a transition period from high school to university life. During this stage, they need certain skills to adjust to the academic environment at university. Coelho and Romão (2017) state that intervention in this phase is needed since school transition may have a negative effect on students' selfconcept.

\footnotetext{
* Paper Info: Revised: March 9, 2019

Accepted: June 22, 2019

* Corresponding author: Rifa Hidayah

E-mail: rifa_hidayah@psi.uin-malang.ac.id

Affiliation: Universitas Islam Negeri Maulana Malik Ibrahim Malang, Indonesia
} 
University students are adolescents who undergo more intensive interactions and become more sensitive to their peers than before (Newman \& Newman, 2005). Studying at university involves an uneasy socialization process, such as the adjustment to new fiends, academic life, and university environment.

The new students at the faculty of Psychology in UIN Maulana Malik Ibrahim Malang, Indonesia, should stay in Ma'had Al Aly (Islamic boarding school) which is located in the university area. It is a mandatory rule for all new students in UIN Maulana Malik Ibrahim Malang since the university aims to emphasize the importance of good character building and strong religiosity. The students living in M'had Al Aly need to adjust to various aspects: academic, self-performance, lectures, peers, and societies within the university. In addition, the success of students' social adjustment can contribute to the success of their studies at the university. Curran's (2018) study confirms that there is a positive correlation between cognitive flexibility and social adjustment.

First-year students' successful adjustment can lead to the happiness however their failure may contribute to social adjustment conflicts. Social adjustment is a pivotal aspect of one's quality life (Curran, 2018). Such adjustments may be influenced by many factors, for example, physical, psychological, culture, and religion (Schneiders, 1964). In addition, the psychological condition also plays a significant role in students' successful social adjustment. Students with a high quality of self-concept can corroborate their social interactions in the university environment better which can also facilitate and improve their social adjustment. Self-concept is the key point to develop autonomous learning (Mynott, 2018), which has a positive correlation with psychological adjustment (Fuentes, García, Gracia, \& Lila, 2011). Students who possess high quality self-concept can recognize their strengths and weaknesses so they are able to develop positive attitudes and good social adjustment. Hence, to further investigate first-year students' self-concept and social adjustment in the faculty of Psychology, UIN Maulana Malik Ibrahim Malang is important to carry out the present research.

This paper attempts to understand a) the degree of first-year students' social adjustment at the faculty of psychology, UIN Maulana Malik Ibrahim Malang, b) the quality of self-concept of first-year students of the faculty of psychology, UIN Maulana Malik Ibrahim Malang, and 3) the correlation between students' selfconcept and social adjustment. This study is expected to provide students with detailed information of selfconcept and social adjustment so that potential problems they may encounter can be solved. In addition, this paper also aims to encourage educational institutions to pay more attention to students' self-development.

\section{Literature Review}

Social adjustment is the ability to cope with the social environment (Campbell, Assanand, \& Paula, 2003) which is essential in establishing good social interactions (Schneiders, 1964). Successful adjustment relies much on self-concept, a perspective towards one's own competence (Eccles, 2005), or an evaluation of oneself (Tang, 2011), and an individual assessment (Hughes, Galbraith, \& White, 2011).

The influence of self-concept on social adjustment can be explained through social comparison theory which was developed by Festinger (Shaw, 1970). That theory states that social influence is derived from one's evaluation of themselves by comparing themselves to other individuals. The prominent source of information are parents, peers, and societies (Calhoun, 1990). To adjust to social life, a person tends to compare themselves to, for example, his/her peers who have similar traits. By such comparison, an individual can evaluate him/herself so that an understanding of self-concept can be gained. A good quality self-concept may be helpful for better social adjustment.

An individual who has a positive self-concept can therefore recognize him/herself (Calhoun, 1990), so he/she can develop good attitudes during his/her social adjustment. In addition, it will also contribute to good social relationships. Another factor that affects self-concept is one's environment. For students, for example, a good academic environment and atmosphere may help them establish positive self-concept which is important for social adjustment in the university. 
This paper therefore formulates the hypothesis as "An individual with a high degree of social-concept will has a better social adjustment process".

\section{Research Methodology}

The subjects of this study include 134 first-year students studying Psychology at UIN Maulana Malik Ibrahim Malang, East Java, collected through random sampling. The social adjustment scale is set in accordance to Schneiders' (1964) criteria; understanding and recognition of others' rights, making good friends and keeping friendships (participation), having interest and empathy in others' social welfare (social approval), prioritizing others' interest to oneself (altruism), and respecting values, laws, norms, and cultures of the society (conformity).

Self-concept is an individual evaluation of oneself, towards what is thought and felt. The scale of selfconcept is arranged based on Calhoun's (1990) classifications: knowledge, hope, and evaluation. The scale of social adjustment consists of 51 valid and reliable items out of 56. Reliability is measured according to an Apha cronbach technique and has the following results; $\mathrm{a}=0.913$ with high differentiation ( $\mathrm{r} 0.301$ to $0.533, \mathrm{r}$ $>0.300$ ). It also shows a positive correlation with $\mathrm{p}<0.05$.

The scale of self-concept consists of 54 valid items out of 60 . Reliability is measured by employing an Apha technique which results in á $=0.929$, being very reliable. This demonstrates a positive correlation of $p<$ 0.05 and a high differentiation (r 0.321 to 0.599 ).

Karl Pearson's product-moment analysis was employed to examine the relationship between self-concept and social adjustment among first-year students using the SPSS program.

\section{Results}

The social adjustment level of the first-year students at the psychology faculty of Universitas Islam Negeri Maulana Malik Ibrahim Malang are shown below.

The percentage of student's social adjustment levels is illustrated in figure 1

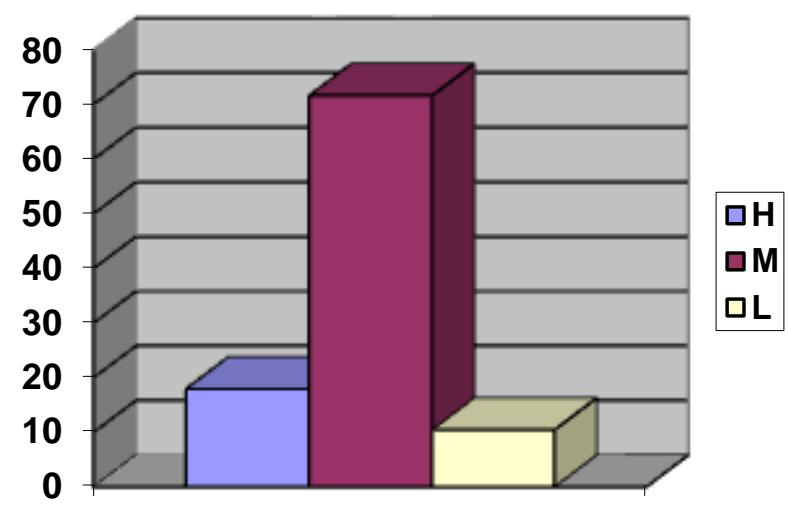

Figure 1. Student's social adjustment levels

The highest percentage of the student's social adjustment was $71.652 \%$ (96 subjects), and the intermediate level was $17.910 \%$ (24 students), and the lowest was $10.447 \%$ (14 students).

The self-concept level of the first-year students of the psychology faculty of UIN Maulana Malik Ibrahim Malang are shown below.

The percentage of students' self-concept levels is indicated in figure 2:

Global J. Bus. Soc. Sci. Review 7 (2) 125 -130 (2019) 


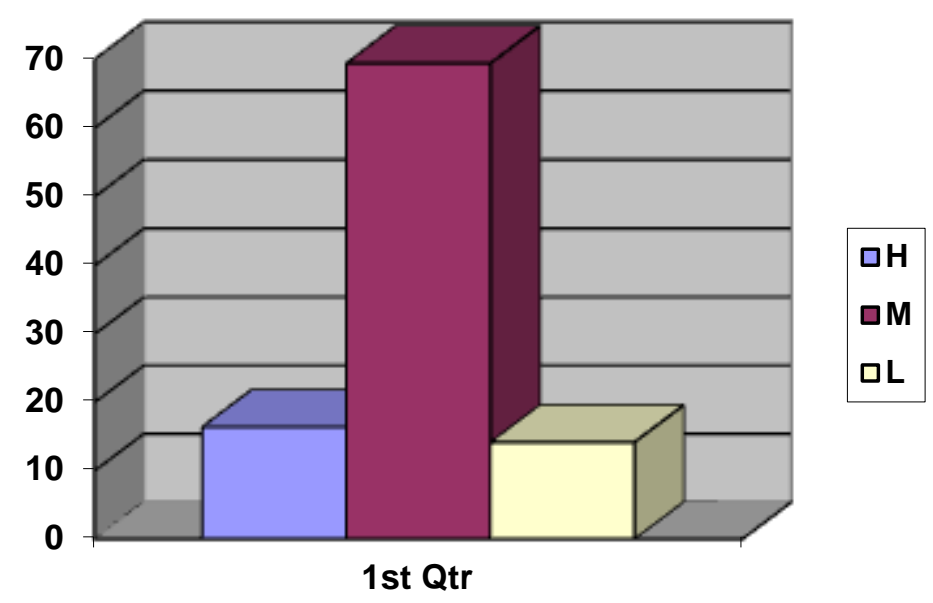

Figure 2. The students' self-concept levels

The highest self-concept level of the first-year students was 93 subjects $(69.402 \%)$, and the medium level was 22 subjects (16.417\%), and the lowest one was 19 subjects (14.179\%).

\subsection{The relationship between students' self-concept and social adjustment}

The results of data analysis show that there is a very significant relationship between self-concept and social adjustment among first-year students of the psychology faculty of UIN Maulana Malik Ibrahim Malang (p: 0.000 rxy: 0.703). In other words, the hypothesis is confirmed. Other studies have shown that, based on Pearson correlation, rxy is 0.703 , which means that self-concept contributes to $70.3 \%$ of one's social adjustment and the remaining $29.7 \%$ of social adjustment is influenced by other factors.

\section{Discussion}

The present study demonstrates that there is a positive relationship between the self-concept and social adjustment among first-year students in UIN Maulana Malik Ibrahim Malang. The effect of self-concept on social adjustment is quite high, at $70.3 \%$. A high quality self-concept enables students to thrive in a social adjustment situation. Students need to do a variety of positive activities, such as active involvement in organizations on and off campus, for example, activities on the student executive board or through student activity units. Active involvement in well-organized activities will reduce loneliness (Bohnert, Aikins, \& Edidin, 2007), and will result in better quality interactions (Stanley \& Bohnert, 2011), and will therefore make social adjustment easier for those students. Further, there is a positive relationship between cognitive flexibility and social adjustment (Curran, 2018).

Universities need to equip their first-year students with the necessary skills to achieve social adjustment. Various kinds of preventive activities are of great importance in that regard, including understanding students needs and easing difficulties they may encounter at the beginning of their academic journey through the provision of counselling and other measures. Curative efforts are made when individuals experience social adjustment difficulties. In addition, the university's codes of conduct must be provided to all students to enable them to understand the prevailing regulations therein.

However, if students demonstrate improper social adjustment, special assistance by professionals and/or therapists are provided. Din et. al.'s (2015) study suggests that there is a very significant relationship ( $\mathrm{p}=$ 0,000 ) between social adjustment and psychosocial rehabilitation, demonstrating the significance of social adjustment. 
Students with a positive self-concept will find it easier to avoid negative behavior. A positive self-concept will affect the way an individual behaves and reacts. Yazdani and Daryei (2016) indicate that teenagers with a higher quality of self-concept are more likely to avoid depression, anxiety and stress, compared to ordinary teenagers. Magdalena (2013) has also confirmed the positive correlation between academic adjustment and self-esteem.

This study also has shed the light on the fact that social support and individual differences have quite a significant (29.7\%) influence on social adjustment. This is consistent with conclusions made in Hosseinizadeh's (2014) research which highlights the relationship between differences among individuals with social adjustment. Good social adjustment requires social support, such as from parents and lecturers. Abbas et. al. (2019) further highlight the considerable importance of social support for positive marital adjustments. In addition, self-esteem and social competence are considered to play a crucial role in influencing one's interpersonal qualities (Paz et. al., 2017; Umberson \& Montez, 2010).

\section{Conclusion}

Some efforts is needed to improve students' self-concept and social adjustment. Steps must be taken by several key parties, including parents, the government, society, and the university. Parents should provide opportunities to their teenagers to develop themselves and socialize with the community at large. In addition, students' material, psychological and spiritual needs must be fulfilled to avoid problem behaviors.

For universities, it is essential that students be provided with facilities to develop themselves, such as social workers, effective counseling facilities, integrated learning centers, and so forth. Continuous advertisement of the prevailing norms and rules must be used to promote the importance of these phenomenon in academic life. Further, providing both material and immaterial appreciation for each student's achievement as well as providing psychological and religious counselling must be a top priority of the university.

Future research should place stronger emphasis on other variables that influence self-concept, including: social support, self-esteem and individual differences. Furthermore, further studies should include not only samples from higher education institutes but also community members at large, with a particular focus on teenagers in areas with a non-tertiary education background. It is equally important that future research be able to investigate this issue in greater depth.

\section{References}

Abbas, J., Aqeel, M., Abbas, J., Shaher, B., Jaffar, A., Sundas, J., \& Zhang, W. (2019). The moderating role of social support for marital adjustment, depression, anxiety, and stress: Evidence from Pakistani working and nonworking women. Journal of affective disorders, 244, 231-238.https://doi.org/10.1016/j.jad.2018.07.071

Ahmad, S., \& Naqvi, I. (2016). Moderating impact of social adjustment on the relationship between sensation seeking and behaviour problems among adolescents. Pakistan Journal of Psychological Research, 31(1). https://www.questia.com/library/journal/1P3-4183151961/moderating-impact-of-social-adjustment-on-the-relationship

Bohnert, A. M., Aikins, J. W., \& Edidin, J. (2007). The role of organized activities in facilitating social adaptation across the transition to college. Journal of Adolescent Research, 22(2), 189-208. https://doi.org/10.1177/0743558406297940

Calhoun, J. F., \& Acocella, J. R. (1990). Psychology about adjustment and human relations (third edition). Satmoko, New York Hospital (Translator): McGraw-Hill.

Campbell, J. D., Assanand, S., \& Paula, A. D. (2003). The structure of the self-concept and its relation to psychological adjustment. Journal of personality, 71(1), 115-140. https://doi.org/10.1111/1467-6494.t01-1-00002

Coelho, V.A., \& Romão, A. M. (2017). The Impact of Secondary School Transition on Self-Concept and Self- Esteem The impact of school transition to the 2nd cycle on self-concept and self-esteem. Journal of Psychodidactics, 22 (2). Retrieved from http://www.ehu.eus/ojs/index.php/psicodidactica/article/view/16250 
Curran, T. (2018). An actor-partner interdependence analysis of cognitive flexibility and indicators of social adjustment among mother-child dyads. Personality and Individual Differences, 126, 99-103. https://doi.org/10.1016/j.paid.2018.01.025

Din, S., Shah, M., Jamal, H., \& Bilal, M. (2015). Rehabilitation and social adjustment of people with burns in society. Burns, 41(1), 106-109. https://doi.org/10.1016/j.burns.2014.04.020

Eccles, J. S. (2005). Studying the development of learning and task motivation. Learning and Instruction, 15(2), 161171. https://doi.org/10.1016/j.learninstruc.2005.04.012

Fuentes, M.C., García, J.F., Gracia, E., \& Lila, M. (2011). Self-concept and psychosocial adjustment in adolescence. Psicothema, 23 (1), 7-12.

Hosseinizadeh, M. (2014). Examining the relationship between differentiation of self-components and social adjustment. Procedia-Social and Behavioral Sciences, 113, 84-90.https://doi.org/10.1016/j.sbspro.2014.01.014

Hughes, A., Galbraith, D., \& White, D. (2011). Perceived competence: A common core for self-efficacy and selfconcept?. Journal of Personality Assessment, 93(3), 278-289. https://doi.org/10.1080/00223891.2011.559390

Magdalena, S. M. (2013). Social and emotional competence-predictors of school adjustment. Procedia-Social and Behavioral Sciences, 76, 29-33.https://doi.org/10.1016/j.sbspro.2013.04.068

Mynott, G. J. (2018). The academic self-concept of business and management students: A review of the literature. The International Journal of Management Education, 16(3), 515-523.https://doi.org/10.1016/j.ijme.2018.10.003

Newman, B., \& Newman, P. (2005). Development Through Life: A Psychosocial Approach. Cengage Learning. Paz, V., Nicolaisen-Sobesky, E., Collado, E., Horta, S., Rey, C., Rivero, M., Gradin, V. B. (2017). Effect of self-esteem on social interactions during the Ultimatum Game. Psychiatry Research, 252, $247-255$. https://doi.org/10.1016/j.psychres.2016.12.063

Schneiders, A. A. (1964). Personal Adjustment and Mental Health. Holt, Rinehart and Winston.

Shaw, M. E. (1970). Theories of social psychology. McGraw-Hill Book Company.

Stanley, C., \& Bohnert, A. (2011). The Moderating Effects of Organized Activities on the Relations between Body Mass and Social Adjustment in Adolescents. North American Journal of Psychology. Retrieved from https://ecommons.luc.edu/psychology_facpubs/24

Tang, S. F. (2011). The relationships of self-concept, academic achievement and future pathway of first year business studies diploma students. International Journal of Psychological Studies, 3(2), 123.https://doi.org/10.5539/ijps.v3n2p123

Umberson, D., \& Karas Montez, J. (2010). Social relationships and health: A flashpoint for health policy. Journal of health and social behavior, 51(1_suppl), S54-S66. https://doi.org/10.1177/0022146510383501

Yazdani, S., \& Daryei, G. (2016). Parenting styles and psychosocial adjustment of gifted and normal adolescents. Pacific Science Review B: Humanities and Social Sciences, 2(3), 100-105. https://doi.org/10.1016/j.psrb.2016.09.019 